\title{
Photodynamic Therapy with Phthalomethyl D: Perspectives against SARS-CoV-2
}

\author{
Marcus Vinicius de Mello Pinto ${ }^{*}$, Carlos Henrique Machado Bittencourt Silva ${ }^{2}$, \\ Aline Ronis Sampaio1, Miriam Viviane Baron³, Alexandre Gomes Sancho ${ }^{4}$, Esteban Fortuny5, \\ Lizia Fabiola Almeida Silva ${ }^{6}$, Felice Picariello7 ${ }^{7}$, Rogério Mendonça de Carvalho ${ }^{8}$ \\ ${ }^{1}$ Instituto Celulare, Rio de Janeiro, RJ, Brazil \\ ${ }^{2}$ Orthopedics, Universidade Federal Fluminense (UFF), Rio de Janeiro, RJ, Brazil \\ ${ }^{3}$ Post-Graduate Program in Medicine and Health Sciences, Pontifícia Universidade Católica do Rio Grande do Sul (PUCRS), Porto \\ Alegre, RS, Brazil \\ ${ }^{4}$ Universidade do Grande Rio (Unigranrio), Rio de Janeiro, RJ, Brazil \\ ${ }^{5}$ Universidad Finis Terrae; Clínica Diagnostra, Santiago do Chile, Chile \\ ${ }^{6}$ Brazilian National Research Ethics Committee (Conep), Brasília, DF, Brazil \\ ${ }^{7}$ Università degli Studi di Napoli Federico II, Naples, Italy \\ ${ }^{8}$ Universidade Federal de Uberlandia, MG, Brazil \\ Email: *marcuspinto1966@gmail.com
}

How to cite this paper: de Mello Pinto, M.V., Silva, C.H.M.B., Sampaio, A.R., Baron, M.V., Sancho, A.G., Fortuny, E., Silva, L.F.A., Picariello, F. and de Carvalho, R.M. (2020) Photodynamic Therapy with Phthalomethyl D: Perspectives against SARS-CoV-2. Journal of Biosciences and Medicines, 8, 104-116. https://doi.org/10.4236/jbm.2020.810010

Received: September 14, 2020

Accepted: October 18, 2020

Published: October 21, 2020

Copyright $\odot 2020$ by author(s) and Scientific Research Publishing Inc. This work is licensed under the Creative Commons Attribution International License (CC BY 4.0).

http://creativecommons.org/licenses/by/4.0/ (c) (i) Open Access

\begin{abstract}
Background: Photodynamic therapy (PDT) is the generation of cytotoxic agents through the dynamic interaction between a photosensitizer excited by light at a specific wavelength. When associated with phthalocyanines, they are efficient in incorporating target cells and exhibiting high rates of triplet generation. This study aimed to characterize PDT associated with the phototherapeutic agent Phthalomethyl $\mathrm{D}$, developed by the authors, in the process of repair, healing and immune improvement for possible application against SARS-CoV-2. Methods: Sixty-nine mice were used, divided into 2 groups: GI, treated with ILIB laser, without a phototherapeutic agent, and subjected to surgery for viral induction; GII, same as GI plus association of Phthalomethyl D. They were divided into subgroups and reevaluated at 7,14 , and 21 days, and then divided into 3 subgroups of 6 animals each, subjected to treatment at 24 h, 48 h, 72 h, 5 and 7 days. Results: Both groups had a high rate of partial incision closure and acute inflammatory control. Microscopically, there was a greater amount of amorphous fundamental substance, fibrocytes, fibroblasts, and giant cells and reduction in the number of keratinocytes, in the amount of keratin, and epidermal thickness in GII than in GI. Conclusions: PDT with Phthalomethyl D stimulates the processes of healing/repair and immunomodulation during viral infection, initially favoring the inflammatory response and, after 21 days, contributing to the an-
\end{abstract}


ti-inflammatory response profile, making this approach possible in the treatment of individuals infected with SARS-CoV-2.

\section{Keywords}

Photodynamic Therapy, Coronavirus, Phthalocyanines, Methylene Blue, Vitamin D, Phthalomethyl D

\section{Introduction}

The recent global new coronavirus (SARS-CoV-2) pandemic has frightened communities around the world due to its high rates of transmissibility and death, leading to countless economic, psychosocial, and catastrophic consequences [1]. Because it is an unknown, recent and devastating pathology, there is no effective treatment or prevention for SARS-CoV-2 infection, requiring rapid mobilization and investigation of potential substances and clinical tools, including photodynamic therapy (PDT) [2] [3] [4].

PDT involves the administration of a photosensitizer or phototherapeutic agent to a diseased tissue of interest, followed by the photoactivation of that agent by a coherent laser light source or light-emitting diode at a specific wavelength [5]. When a photochemical cell reaction occurs, it is used to selectively destroy the target tissue [6] [7] [8]. Phthalocyanines (Pcs), porphyrin analogues, are the second generation of photosensitive substances that have been used in the treatment of skin diseases, such as basal cell carcinoma, psoriasis and actinic keratosis, and bacterial and viral manifestations, often showing positive results in reducing injury with minimal or no toxicity [9] [10] [11]. However, PDT has been little explored and, after extensive bibliographic research, we have not been able to find a report of its use in biological models of SARS-CoV-2.

PDT has been successfully used in previous pandemics, such as that from 1918, and in other coronavirus-like infections with an impact-reduction effect [12] [13], but this seems to have been forgotten or "left out". Recent studies have shown its potential effect on the treatment of different bacteria and viruses, including the coronavirus [14] [15] [16] [17] [18].

This study aimed to use experimental models of poxvirus infection to determine whether the use of PDT associated with the phototherapeutic agent Phthalomethyl D, developed by the authors, would be effective in the process of repair, healing and immune improvement induced by poxviruses in mice. Based on the findings of the literature and those found in our work, we believe in the enormous potential of this proposed therapy associated with Phthalomethyl $\mathrm{D}$ as an experimental model in the treatment against SARS-CoV-2 and similar coronavirus infections.

\section{Methods}

We used a mouse model of poxvirus infection to study the effect of PDT com- 
bined with aluminum phthalocyanine (AlPc), methylene blue (MB), and vitamin $\mathrm{D}$, through Phthalomethyl $\mathrm{D}$, on the processes of healing/repair and immunomodulation. The study was approved by the Institutional Animal Care and Use Committee of Centro Universitário de Caratinga in Minas Gerais, Brazil.

\subsection{Inducing Poxvirus Infection in Mice}

Sixty-nine 2-month-old male BALB/c mice were housed in individual cages and maintained under a 12-h light-dark cycle and a temperature of $22^{\circ} \mathrm{C}$, with free access to food and water. All animals underwent surgery for viral induction with poxviruses, which comprise a family of linear double-stranded DNA genome viruses ranging from 140,000 to 370,000 base pairs (bp). They have a complex morphology and replicate exclusively in the cell cytoplasm. The prototype of the family Poxviridae is the vaccinia virus (VACV) belonging to the viral subfamily. For surgery, the mice were anesthetized with pentobarbital $(50 \mathrm{mg} / \mathrm{kg}$ intraperitoneally), and lidocaine $(0.5 \mathrm{mg} / 20 \mathrm{gs.c})$ was used for local anesthesia. Under aseptic conditions, a $1-\mathrm{cm}$ ventral incision was made to implant a $13-\mathrm{mm}$ sterile round glass coverslip subcutaneously. The incision was closed with $1 / 04$ metric absorbable suture.

The mice were randomly divided into 2 groups: group I $(n=35)$, treated with PDT without the use of a phototherapeutic agent; and group II $(n=34)$, treated with PDT with the use of Phthalomethyl D, which was administered orally or introduced into the digestive tract through a $4-\mathrm{cm}$ flexible esophageal or stomach tube (gavage). Small volumes ( $1 \mathrm{~mL} / 100 \mathrm{~g}$ body weight) were administered at the beginning of the light cycle (resting phase) 10 times for $30 \mathrm{~min}$. Mice were divided into subgroups and sacrificed with a lethal dose of pentobarbital at 7, 14, and 21 days after viral induction.

\subsection{PDT and Laser Irradiation}

PDT was performed with an intravascular laser irradiation of blood (ILIB) prototype through the radial artery for $30 \mathrm{~min}$ at a wavelength of $660-460 \mathrm{~nm}, 100$ $\mathrm{mW}$ output power, and in continuous wave mode for spot irradiation (Ecco Fibras, São Paulo, SP, Brazil). Spot irradiation was performed in contact with the skin at room temperature $\left(22^{\circ} \mathrm{C}\right)$. Mice had free food and water access for $24 \mathrm{~h}$ before receiving PDT, for which they were divided into 3 subgroups of 6 mice each. All subgroups were subjected to PDT with ILIB at 24,48 , and $72 \mathrm{~h}$, and at 5 and 7 days after subcutaneous implantation of the glass coverslips. Two subgroups continued to receive PDT with ILIB at 14 days after surgery, and only 1 subgroup was treated at 21 days.

\subsection{Assessment of Healing/Repair and Immunomodulation}

Mice were examined clinically at $48 \mathrm{~h}$ and 5 days postoperatively for assessment of the healing/repair process. Images were acquired with a Nikon-Coolpix 4500 digital camera for histological investigation. After euthanasia, the surgical scar 
was resected to remove the coverslips, which were fixed in $3.5 \%$ formaldehyde for $1 \mathrm{~h}$ and stained with hematoxylin-eosin (HE). The slides were viewed in a Zeiss Ultraphot microscope at $40 \times$ magnification for histomorphometric analysis. The coverslips were photographed with a Nikon-Coolpix 4500 digital camera coupled to an Olympus microscope. The number of cells was counted using Image-Pro Plus software (Media Cybernetics, Silver Spring, USA), and the following criteria were evaluated: number of giant cells, number of nuclei present in giant cells, amount of collagen/fibrin, and numbers of monocytes/fibroblasts, plasma cells, neutrophils, and lymphocytes.

\subsection{Statistical Analysis}

Counts are presented as the frequency of the analyzed variables. The association between variables was investigated by Pearson's chi-square test. $\mathrm{P}$ values $\leq 0.05$ were considered significant. All analyses were performed with SigmaStat, version 1.0 (Jandel Scientific).

\section{Results}

At $48 \mathrm{~h}$ after surgery, gross examination of incision closure revealed the presence of blood clots in $60 \%$ of mice in group II (PDT + Phthalomethyl D). Both groups had a high rate of partial incision closure and acute inflammatory control $(93.3 \%$ in group II vs. $73.3 \%$ in group I). One mouse died in group II, against none in group I. The suture was preserved in all animals, regardless of the type of treatment. At 5 days, incision closure was significantly different between groups (70\% of mice in group II had complete closure vs. $41.6 \%$ in group I). In group I, the incision was visible in $33.3 \%$ of mice, and noticeable despite hair in $57.7 \%$. In group II, the incision was visible in 50\%, noticeable despite hair in $43.3 \%$, and nonvisible but palpable in $6.7 \%$ (Table 1 ).

Microscopically, there was a greater amount of amorphous fundamental substance, fibrocytes, and fibroblasts and a reduction in epidermal thickness, in the number of keratinocytes, and in the amount of keratin in group II compared with group I (Figure 1). An inflammatory infiltrate was present in mice in group II, although smaller and with greater circulatory response.

The number of giant cells was significantly higher in group II than in group I. Both groups showed an increase in the number of giant cells at 14 days after implantation of the glass coverslip, and a decrease in these values at 21 days. Regardless of the type of treatment and postoperative assessment time point, most cells tended to have 2 to 5 nuclei. However, when treatment type and time point were considered, giant cells with more nuclei were detected in group II and at 14 days after surgery (Table 2).

Because of difficulties in distinguishing cells and fibrous material in the histomorphometric analysis of the HE-stained specimens, monocytes, macrophages and fibroblasts were grouped into one cluster, while fibrin and collagen were grouped into another cluster. The number of monocytic cells/fibroblasts was 
Table 1. Macroscopic parameters at $48 \mathrm{~h}$ and 5 days after surgery in poxvirus-infected mice receiving photodynamic therapy with (treated, $\mathrm{n}=34$ ) and without (untreated, $\mathrm{n}=35$ ) Phthalomethyl $\mathrm{D}$.

\begin{tabular}{|c|c|c|c|c|c|c|c|}
\hline \multirow{2}{*}{ Time point } & \multirow{2}{*}{\multicolumn{2}{|c|}{ Parameters }} & \multicolumn{2}{|c|}{ Absolute number } & \multicolumn{2}{|c|}{$\%$} & \multirow{2}{*}{$x^{2}$} \\
\hline & & & Untreated & Treated & Untreated & Treated & \\
\hline \multirow{6}{*}{48 hours } & \multicolumn{2}{|c|}{ Presence of blood clots } & 0 & 9 & $0 \%$ & $60 \%$ & $17.4^{\star}$ \\
\hline & \multicolumn{2}{|c|}{ Preserved suture } & 35 & 34 & 100 & 100 & 0 \\
\hline & \multirow{4}{*}{ Incision closure } & Absent & 0 & 0 & 0 & 0 & - \\
\hline & & Initial closure $(<2 / 3)$ & 1 & 4 & 6.66 & 26.6 & $21.3^{*}$ \\
\hline & & Partial closure $(\geq 2 / 3)$ & 35 & 34 & 93.3 & 73.3 & 1.3 \\
\hline & & Complete closure & 0 & 0 & 0 & 0 & - \\
\hline \multirow{8}{*}{5 days } & \multirow{5}{*}{ Incision closure } & Absent & 0 & 0 & 0 & 0 & - \\
\hline & & Initial closure $(<2 / 3)$ & 0 & 0 & 0 & 0 & - \\
\hline & & Partial closure $(\geq 2 / 3)$ & 8 & 6 & 53.3 & 40.0 & $8.6^{*}$ \\
\hline & & Complete closure & 7 & 9 & 46.6 & 60.0 & $6.6^{*}$ \\
\hline & & Visible & 5 & 6 & 34.5 & 40.0 & $12.06^{*}$ \\
\hline & \multirow{3}{*}{$\begin{array}{l}\text { Macroscopic appearance } \\
\text { of the incision }\end{array}$} & Noticeable despite hair $(<2 / 3)$ & 10 & 8 & 66.6 & 53.3 & $4.93^{*}$ \\
\hline & & Nonvisible but palpable $(\geq 2 / 3)$ & 0 & 1 & 0 & 6.66 & $28.06^{*}$ \\
\hline & & Nonvisible and nonpalpable & 0 & 0 & 0 & 0 & - \\
\hline
\end{tabular}

${ }^{*}$ Chi-square values calculated for the association between laser application/non-application and time points, significant at $5 \%$ with a degree of freedom.

Table 2. Giant cell counts in the inflammatory infiltrate at 7, 14, and 21 days after surgery in poxvirus-infected mice receiving photodynamic therapy with (treated, $\mathrm{n}=34$ ) and without (untreated, $\mathrm{n}=35$ ) Phthalomethyl D.

\begin{tabular}{|c|c|c|c|c|c|c|c|}
\hline \multirow{2}{*}{\multicolumn{2}{|c|}{ Time point/group }} & \multicolumn{4}{|c|}{ Number of giant cell nuclei } & \multicolumn{2}{|c|}{ Number of giant cells } \\
\hline & & 2 to 5 & 6 to 10 & 11 to 15 & $>15$ & $\mathbf{n}$ & Chi-square \\
\hline \multirow[b]{2}{*}{7 days } & Untreated & 8 & 2 & 0 & 1 & 9 & \multirow[b]{2}{*}{$15^{*}$} \\
\hline & Treated & 27 & 6 & 1 & 2 & 34 & \\
\hline \multirow{2}{*}{14 days } & Untreated & 23 & 19 & 5 & 5 & 52 & \multirow{2}{*}{$18^{*}$} \\
\hline & Treated & 76 & 31 & 7 & 6 & 123 & \\
\hline \multirow{2}{*}{21 days } & Untreated & 15 & 11 & 0 & 2 & 29 & \multirow[b]{2}{*}{$23^{*}$} \\
\hline & Treated & 28 & 19 & 7 & 8 & 64 & \\
\hline
\end{tabular}

${ }^{*}$ Chi-square values calculated for the association between laser application/non-application and time points, significant at $5 \%$ with a degree of freedom.

significantly higher at all postoperative assessment time points in group I than in group II (Figure 2). Also, in both groups, the number of these cells increased from day 5 to day 14, with a decline in the last experimental week only in mice in group I (Table 3).

\section{Discussion}

Treatment is based on exposure of the site to light at a wavelength that corresponds 

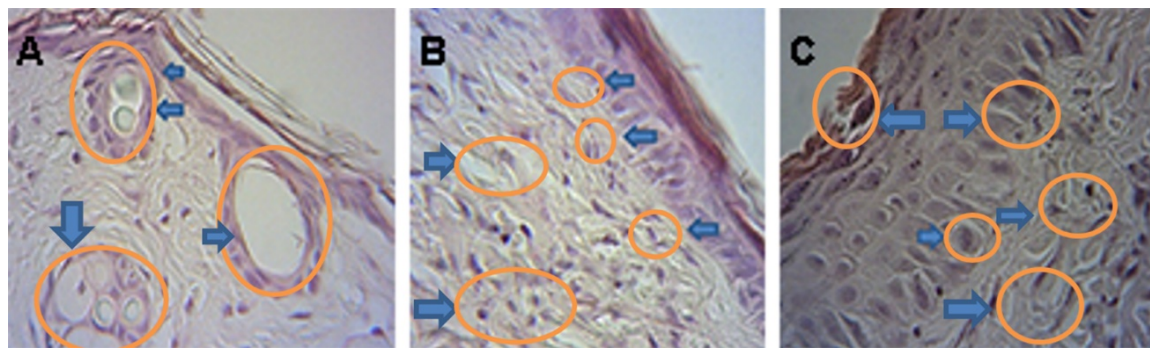

Figure 1. Photomicrographs of the skin of BALB/c mice treated without (GI) and with Phthalomethyl D (GII). (A) Group I (40×). Blue arrows indicate epithelial thickening with an important balance of inflammatory infiltrates. (B) Group II (40×), Phthalomethyl D. The blue arrows indicate epithelial thickening with an important balance of inflammatory infiltrates. (C) Group I $(40 \times)$. The blue arrows indicate hypertrophy of epidermal cells and increased singlet oxygen delivery.

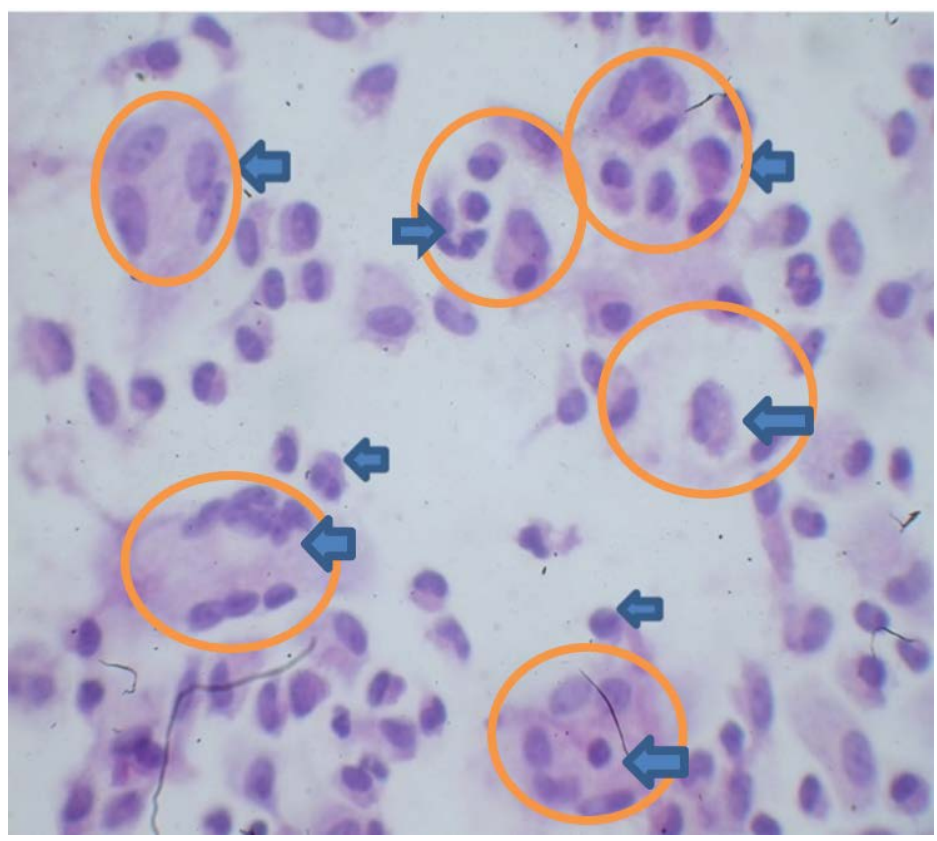

Figure 2. Photomicrograph after 21 days of photodynamic therapy showing Phthalomethyl D leukocyte response. The arrows indicate the responses of granular tissue, mast cells, leukocytes, and inflammatory defenses.

Table 3. Numbers of monocytic cells/fibroblasts, fibrous material, and inflammatory infiltrating cells at 7, 14, and 21 days after surgery in poxvirus-infected mice receiving photodynamic therapy with (treated, $\mathrm{n}=34$ ) and without (untreated, $\mathrm{n}=35$ ) Phthalomethyl D.

\begin{tabular}{cccccccccccccccccc}
\hline \multicolumn{1}{c}{$\begin{array}{c}\text { Monocytic } \\
\text { cells/fibroblasts (fibrin/collagen) }\end{array}$} & \multicolumn{1}{c}{ Fibrous material } & \multicolumn{1}{c}{ Lymphocytes } & Plasma cells & \multicolumn{3}{c}{ Neutrophils } \\
\hline Time point & UT & T & $\chi^{2}$ & UT & T & $\chi^{2}$ & UT & T & $\chi^{2}$ & UT & T & $\chi^{2}$ & UT & T & $\chi^{2}$ \\
\hline 7 days & 1109 & 887 & $23^{*}$ & 704 & 252 & $214^{*}$ & 18 & 43 & $10^{*}$ & 24 & 72 & $24^{*}$ & 7 & 11 & 1 \\
14 days & 1429 & 1133 & $34^{*}$ & 145 & 175 & $4^{*}$ & 5 & 60 & $47^{*}$ & 13 & 78 & $26^{*}$ & 2 & 0 & 2 \\
21 days & 1344 & 1292 & $20^{*}$ & 123 & 228 & $34^{*}$ & 49 & 31 & $4^{*}$ & 19 & 51 & $15^{*}$ & 0 & 0 & - \\
\hline
\end{tabular}

T, treated; UT, untreated. ${ }^{*} \mathrm{p}<0.05$ for the chi-square test, untreated $\times$ treated at different time points. 
to the absorption wavelength of the photosensitizer. This activated agent transfers energy to the triplet molecular oxygen, which, after photoexcitation, is converted into singlet oxygen, generating reactive oxygen species (ROS). The subsequent oxidation of lipids, amino acids and proteins induce cell necrosis and apoptosis. In addition, ROS indirectly stimulate the transcription and release of inflammatory mediators [3] [5] [6] [7] [19] [20]. The absorption of photons emitted by laser irradiation may lead to the promotion of the phototherapeutic agent or photosensitizer from its ground state to the short-lived excited singlet state. When a photochemical cell reaction occurs, it is used to selectively destroy the target tissue. It is a two-stage treatment, where the photosensitizer is administered systemically or topically and preferably accumulates in the injured cells [5]. Afterwards, the treatment site is exposed to light at a wavelength that corresponds to the absorption wavelength of the photosensitizer [6] [7] [8]. Inhibition of mitochondrial enzymes seems to be the main event in cell death of PDT [21] [22].

MB is well known as a histological dye, used for many years, and when activated by light, it has an effect against various types of microorganisms [23] [24] [25], including treatment of malaria and schizophrenia [26] [27]. Vitamin D is photosensitive with direct photochemical degradation by mechanisms involving photosensitizers that generate ROS or by indirect effects of light that lead to lipid oxidation, facilitating the action of PDT [28]. Pcs are strong candidates for use in PDT due to their efficient incorporation into target cells, high triplet yields, and optimal tissue penetration by light owing to their high absorption coefficients at the range of 650 to $680 \mathrm{~nm}$ [10] [29] [30]. Pcs include zinc-phthalocyanine $(\mathrm{ZnPc})$, tetrasulfonated aluminum phthalocyanine (AlPcS4), and chloroaluminum phthalocyanine $(\mathrm{AlPcCl})$, which are used to evaluate oxidative stress in cell lines after photodynamic antimicrobial chemotherapy or the antimicrobial activity of the compounds [11] [26] [30]. Previous results suggest that porphyrins are effective in the treatment of leishmaniasis by PDT [31]. In murine and in vitro models, Pcs showed minimal or no toxicity [11].

Laboratory experiments show that light in the blue $400-470 \mathrm{~nm}$ range is antimicrobial against numerous bacteria [14] [15] [16] [17] [32] [33] [34] and has the potential to reduce opportunistic bacterial infections associated with SARS-CoV-2 and other coronavirus infections, as well as red light and near infrared at wavelengths in the range of 600 to $700 \mathrm{~nm}$ and 700 to $1000 \mathrm{~nm}$, respectively, where they have the potential to reduce pulmonary inflammation and fibrosis [35] [36] [37]. Based on these studies, the use of these wavelengths is suggested to inactivate the virus [18] and to treat its complications, such as acute respiratory distress syndrome (ARDS) [4], one of the main causes of death in all coronavirus pandemics, including the SARS-CoV-2 pandemic [36] [37].

One of the most important strategies for the management of SARS-CoV-2 infection is the faster rehabilitation of damaged tissue and oxygenation, antiviral effects and, finally, the reduction or control of the cytokine storm, reducing inflammatory agents. PDT can be used as adjunctive therapy or even as an alterna- 
tive therapy in all of these mechanisms, without side effects or drug interactions [3] [38].

This study provides experimental evidence that PDT performed with a laser at $100 \mathrm{~mW}$ and Phthalomethyl D is effective in improving wound healing and the systemic inflammatory process. The postoperative macroscopic observations of the effects of PDT + Phthalomethyl D on wound healing in poxvirus-infected mice are in accordance with those reported by Balbino et al. [39].

Our results suggest a stimulatory effect of PDT with a laser at $100 \mathrm{~mW}$ and Phthalomethyl D on the formation of giant cells. These results disagree with those of Liang et al., [40] who found that preselected single Chinese hamster ovary (CHO) cells exposed to 740 and $760 \mathrm{~nm}$ laser microbeam generated by a titanium-sapphire laser at 86 and $174 \mathrm{~mW}$ and different time exposures had poor ability to divide and to form giant cells. However, they suggest a relationship between increased giant cell formation and exposure time to PDT and higher power density. Thus, the increase in giant cell counts in our experiment may be explained by the relationship between the exposure time of $30 \mathrm{~min}$ and PDT with a $100-\mathrm{mW}$ power density laser in the radial artery.

When comparing the number of giant cells in the groups analyzed, there arose a doubt about the ability of PDT with $100-\mathrm{mW}$ power density to induce macrophage fusion and giant cell formation, since differences in the frequency of giant cells may result from the fusion of a larger number of macrophages, which would lead to a reduction in their frequency by the production of giant cells with a greater number of cell nuclei. To rule out this possibility and more efficiently establish the relationship between laser action and giant cell formation, we counted the number of nuclei, a method previously used by Kyriakides et al. [41] in their studies of granulomatous inflammation. Because in both groups the number of nuclei per giant cell was equal to 6 - 7 nuclei, it can be suggested that PDT with 100-mW power density and Phthalomethyl D plays a role as a stimulator of macrophage fusion and giant cell formation.

Our findings showed a higher number of monocytes and fibroblasts in mice receiving PDT without a phototherapeutic agent (group I). The lower frequency of macrophages in mice treated with PDT + Phthalomethyl D (group II) may be related to the number of giant cells. Several authors have reported the dose-dependent activation of macrophages in laser therapy. Novoselova et al. [42] investigated the effect of in vitro exposure to low-level laser therapy $(632.8 \mathrm{~nm})$ on the immune cells of mice and suggested that, under low exposure doses, the production of tumor necrosis factor (TNF)-alpha and interleukin (IL)-6 by macrophages increase, superoxide dismutase (SOD) activity is present and nitric oxide levels decrease; in addition, they suggest that laser irradiation may delay the production of reactive nitrogen and oxygen species. Therefore, it can be suggested that, at low doses, the phagocytic activity increases and cell viability decreases after exposure to PDT with 100-mW power density and Phthalomethyl D. In view of the foregoing, the relationship between the action of the laser and the activation of monocytic cells may support our positive 
results and explain the process of systemic inflammation resolution, with more efficient wound closure and a decrease in the number of giant cells from day 14 to day 21 of treatment in mice subjected to PDT $(100 \mathrm{~mW})$ with Phthalomethyl D.

When analyzing the inflammatory infiltrate, we observed an anti-inflammatory effect of PDT $(100 \mathrm{~mW})$ with Phthalomethyl D in the last week of treatment, with a decrease in the number of lymphocytes and plasma cells, whereas the number of these cells increased in the controls. However, it is noteworthy that, throughout the experiment, the number of lymphocytes and plasma cells in mice receiving PDT $(100 \mathrm{~mW})$ with Phthalomethyl D was higher than that of mice receiving PDT without a phototherapeutic agent. It is possible that laser exposure stimulated a pro-inflammatory response in the first 2 weeks of treatment, contributing to the activation and migration of these cells. Among $\mathrm{T}$ and B lymphocytes, T lymphocytes would be activated by the action of PDT (100 $\mathrm{mW}$ ) with Phthalomethyl $\mathrm{D}$, thus releasing cytokines that characterize the Th2 response and, therefore, promote the differentiation of $\mathrm{B}$ lymphocytes into plasma cells. However, these data should be confirmed in future studies aiming to measure cytokines in blood and tissues infected with SARS-CoV-2. The present results suggest an inhibitory role of IL-4 on TNF-alpha, promoting greater macrophage survival and giant cell formation, and also suggest that, when treating patients with PDT $(100 \mathrm{~mW})$ and Phthalomethyl $\mathrm{D}$, there is an increase in homing of $\mathrm{T}$ lymphocytes, mainly Th2 cell homing, which is essential for the treatment of SARS-CoV-2 infection.

\section{Conclusion}

PDT performed with an $100 \mathrm{~mW}$ laser and Phthalomethyl D stimulates the healing/repair and immunomodulation processes during viral infection, favoring the inflammatory response initially and, after 21 days, contributing to the anti-inflammatory response profile. However, in order to better understand these mechanisms, our findings need to be confirmed by new studies using molecular and cellular biology techniques to more accurately identify the kinetics of the inflammatory infiltrate and the pattern of cytokines involved in SARS-CoV-2 infection. We suggest multicenter studies in humans infected with different viruses, including SARS-CoV-2, using phthalomethyl D and an ILIB prototype for application in the radial artery. We suggest a 6-month follow-up for all patients undergoing this new and promising technique.

\section{Acknowledgements}

ECCO FIBRAS BRASIL, for the scientific and technical support.

Mr. Henrique Trajano da Silva Júnior and his company Ecco Fibras Ópticas e Dispositivos, for the research and financial support that made this work possible.

\section{Financial Disclosure}

The authors have no financial relationships relevant to this article to disclose. 


\section{Conflicts of Interest}

The authors have no conflicts of interest to disclose.

\section{References}

[1] Díaz-Castrillón, F.J. and Toro-Montoya, A.I. (2020) SARS-CoV-2/COVID-19: The Virus, the Disease and the Pandemic. Medical Laboratory, 24, 183-205. https://doi.org/10.36384/01232576.268

[2] Mehra, M.R., Desai, S.S., Ruschitzka, F. and Patel, A.N. (2020) Hydroxychloroquine or Chloroquine with or without a Macrolide for Treatment of COVID-19: A Multinational Registry Analysis. The Lancet. https://doi.org/10.1016/S0140-6736(20)31180-6

[3] Fekrazad, R. (2020) Photobiomodulation and Antiviral Photodynamic Therapy as a Possible Novel Approach in COVID-19 Management. Photobiomodulation, Photomedicine, and Laser Surgery, 38, 255-257. https://doi.org/10.1089/photob.2020.4868

[4] Enwemeka, C.S., Bumah, V.V. and Masson-Meyers, D.S. (2020) Light as a Potential Treatment for Pandemic Coronavirus Infections: A Perspective. Journal of Photochemistry and Photobiology B, 207, Article ID: 111891. https://doi.org/10.1016/j.jphotobiol.2020.111891

[5] Calzavara-Pinton, P.G., Venturini, M. and Sala, R. (2007) Photodynamic Therapy: Update 2006. Part 1: Photochemistry and Photobiology. Journal of the European Academy of Dermatology and Venereology, 21, 293-302. https://doi.org/10.1111/j.1468-3083.2006.01902.x

[6] Firczuk, M., Nowis, D. and Golab, J. (2011) PDT-Induced Inflammatory and Host Responses. Photochemical and Photobiological Sciences, 10, 653-663. https://doi.org/10.1039/c0pp00308e

[7] Singh, N., Chander Narula, S., Kumar Sharma, R., Tewari, S. and Kumar Sehgal, P. (2014) Vitamin E Supplementation, Superoxide Dismutase Status, and Outcome of Scaling and Root Planing in Patients with Chronic Periodontitis: A Randomized Clinical Trial. Journal of Periodontology, 85, 242-249. https://doi.org/10.1902/jop.2013.120727

[8] Mostafa, D. and Tarakji, B. (2015) Photodynamic Therapy in Treatment of Oral Lichen Planus. Journal of Clinical Medicine Research, 7, 393-399. https://doi.org/10.14740/jocmr2147w

[9] Fabris, C., Soncin, M., Miotto, G., et al. (2006) Zn(II)-Phthalocyanines as Phototherapeutic Agents for Cutaneous Diseases. Photosensitization of Fibroblasts and Keratinocytes. Journal of Photochemistry and Photobiology B, 83, 48-54. https://doi.org/10.1016/j.jphotobiol.2005.12.006

[10] Gursoy, H., Ozcakir-Tomruk, C., Tanalp, J. and Yilmaz, S. (2013) Photodynamic Therapy in Dentistry: A Literature Review. Clinical Oral Investigations, 17, 1113-1125. https://doi.org/10.1007/s00784-012-0845-7

[11] Zhang, Z., Jin, H., Bao, J., Fang, F., Wei, J. and Wang, A. (2006) Intravenous Repeated-Dose Toxicity Study of ZnPcS2P2-Based-Photodynamic Therapy in Wistar Rats. Photochemical and Photobiological Sciences, 5, 1006-1017. https://doi.org/10.1039/b605516h

[12] Hobday, R.A. and Cason, J.W. (2009) The Open-Air Treatment of Pandemic Influenza. American Journal of Public Health, 99, S236-S242.

https://doi.org/10.2105/AJPH.2008.134627 
[13] (1918) Weapons against Influenza. American Journal of Public Health (NY), 8, 787-788. https://doi.org/10.2105/AJPH.8.10.787

[14] Enwemeka, C.S. (2013) Antimicrobial Blue Light: An Emerging Alternative to Antibiotics. American Journal of Public Health, 31, 509-511. https://doi.org/10.1089/pho.2013.9871

[15] Hamblin, M.R., Viveiros, J., Yang, C., Ahmadi, A., Ganz, R.A. and Tolkoff, M.J. (2005) Helicobacter pylori Accumulates Photoactive Porphyrins and Is Killed by Visible Light. Antimicrobial Agents and Chemotherapy, 49, 2822-2827. https://doi.org/10.1128/AAC.49.7.2822-2827.2005

[16] Bumah, V.V., Masson-Meyers, D.S. and Enwemeka, C.S. (2020) Pulsed $450 \mathrm{~nm}$ Blue Light Suppresses MRSA and Propionibacterium Acnes in Planktonic Cultures and Bacterial Biofilms. Journal of Photochemistry and Photobiology B, 202, Article ID: 111702. https://doi.org/10.1016/j.jphotobiol.2019.111702

[17] de Sousa, N.T., Santos, M.F., Gomes, R.C., Brandino, H.E., Martinez, R. and de Jesus Guirro, R.R. (2015) Blue Laser Inhibits Bacterial Growth of Staphylococcus aureus, Escherichia coli, and Pseudomonas aeruginosa. American Journal of Public Health, 33, 278-282. https://doi.org/10.1089/pho.2014.3854

[18] Schuit, M., Gardner, S., Wood, S., et al. (2020) The Influence of Simulated Sunlight on the Inactivation of Influenza Virus in Aerosols. The Journal of Infectious Diseases, 221, 372-378. https://doi.org/10.1093/infdis/jiz582

[19] Hamblin, M.R. (2017) Mechanisms and Applications of the Anti-Inflammatory Effects of Photobiomodulation. AIMS Biophysics, 4, 337-361.

https://doi.org/10.3934/biophy.2017.3.337

[20] Pinto, M.V.M., et al. (2011) Fototerapia-Aspectos Clinicos da Reabilitacao. Edição: 1. Andreoli.

[21] Morton, C.A. (2004) Photodynamic Therapy for Nonmelanoma Skin Cancer-And More? Archives of Dermatology, 140, 116-120.

https://doi.org/10.1001/archderm.140.1.116

[22] Baldea, I., Olteanu, D.E., Bolfa, P., et al. (2015) Efficiency of Photodynamic Therapy on WM35 Melanoma with Synthetic Porphyrins: Role of Chemical Structure, Intracellular Targeting and Antioxidant Defense. Journal of Photochemistry and Photobiology B, 151, 142-152. https://doi.org/10.1016/j.jphotobiol.2015.07.019

[23] Pereira Gonzales, F., Maisch, T. (2012) Photodynamic Inactivation for Controlling Candida albicans Infections. Fungal Biology, 116, 1-10.

https://doi.org/10.1016/j.funbio.2011.10.001

[24] Chibebe Junior, J., Sabino, C.P., Tan, X., et al. (2013) Selective Photoinactivation of Candida albicans in the Non-Vertebrate Host Infection Model Galleria mellonella. BMC Microbiology, 13, 217. https://doi.org/10.1186/1471-2180-13-217

[25] Prates, R.A., Fuchs, B.B., Mizuno, K., et al. (2013) Effect of Virulence Factors on the Photodynamic Inactivation of Cryptococcus neoformans. PLOS ONE, 8, e54387. https://doi.org/10.1371/journal.pone.0054387

[26] Alexandratou, E., Yova, D. and Loukas, S. (2005) A Confocal Microscopy Study of the Very Early Cellular Response to Oxidative Stress Induced by Zinc Phthalocyanine Sensitization. Free Radical Biology and Medicine, 39, 1119-1127. https://doi.org/10.1016/j.freeradbiomed.2005.06.006

[27] Gardlo, K., Horska, Z., Enk, C.D., et al. (2003) Treatment of Cutaneous Leishmaniasis by Photodynamic Therapy. Journal of the American Academy of Dermatology, 48, 893-896. https://doi.org/10.1067/mjd.2003.218 
[28] Anand, S., Ortel, B.J., Pereira, S.P., Hasan, T. and Maytin, E.V. (2012) Biomodulatory Approaches to Photodynamic Therapy for Solid Tumors. Cancer Letters, 326, 8-16. https://doi.org/10.1016/j.canlet.2012.07.026

[29] Nunes, S.M.T., Sguilla, F.S. and Tedesco, A.C. (2004) Photophysical Studies of Zinc Phthalocyanine and Chloroaluminum Phthalocyanine Incorporated into Liposomes in the Presence of Additives. Brazilian Journal of Medical and Biological Research, 37, 273-284. https://doi.org/10.1590/S0100-879X2004000200016

[30] Escobar, P., Hernandez, I.P., Rueda, C.M., Martinez, F. and Paez, E. (2006) Photodynamic Activity of Aluminium(III) and Zinc(II) Phthalocyanines in Leishmania Promastigotes. Biomedica, 26, 49-56. https://doi.org/10.7705/biomedica.v26i1.1499

[31] Gonçalves, A.C. (2015) Effect of Therapeutic Laser $660 \mathrm{~nm}$ in Experimental Cutaneous Leishmaniasis: Cytokine Expression and Functional Macrophage Profile. Master's Thesis, Universidade Federal de Goiás.

[32] Bumah, V.V., Masson-Meyers, D.S. and Enwemeka, C.S. (2015) Blue $470 \mathrm{~nm}$ Light Suppresses the Growth of Salmonella enterica and Methicillin-Resistant Staphylococcus aureus (MRSA) in Vitro. Lasers in Surgery and Medicine, 47, 595-601. https://doi.org/10.1002/1sm.22385

[33] Mussi, M.A., Gaddy, J.A., Cabruja, M., et al. (2010) The Opportunistic Human Pathogen Acinetobacter baumannii Senses and Responds to Light. Journal of Bacteriology, 192, 6336-6345. https://doi.org/10.1128/JB.00917-10

[34] Maclean, M., MacGregor, S.J., Anderson, J.G. and Woolsey, G. (2009) Inactivation of Bacterial Pathogens Following Exposure to Light from a 405-Nanometer Light-Emitting Diode Array. Applied and Environmental Microbiology, 75, 1932-1937. https://doi.org/10.1128/AEM.01892-08

[35] Guo, Y.R., Cao, Q.D., Hong, Z.S., et al. (2020) The Origin, Transmission and Clinical Therapies on Coronavirus Disease 2019 (COVID-19) Outbreak-An Update on the Status. Military Medical Research, 7, 11. https://doi.org/10.1186/s40779-020-00240-0

[36] Brochetti, R.A., Leal, M.P., Rodrigues, R., et al. (2017) Photobiomodulation Therapy Improves Both Inflammatory and Fibrotic Parameters in Experimental Model of Lung Fibrosis in Mice. Lasers in Medical Science, 32, 1825-1834.

https://doi.org/10.1007/s10103-017-2281-z

[37] de Brito, A.A., da Silveira, E.C., Rigonato-Oliveira, N.C., et al. (2020) Low-Level Laser Therapy Attenuates Lung Inflammation and Airway Remodeling in a Murine Model of Idiopathic Pulmonary Fibrosis: Relevance to Cytokines Secretion from Lung Structural Cells. Journal of Photochemistry and Photobiology B, 203, Article ID: 111731. https://doi.org/10.1016/j.jphotobiol.2019.111731

[38] Biju, T., Shabeer, M.M., Amitha, R., Rajendra, B.P. and Suchetha, K. (2014) Comparative Evaluation of Serum Superoxide Dismutase and Glutathione Levels in Periodontally Diseased Patients: An Interventional Study. Indian Journal of Dental Research, 25, 613-616. https://doi.org/10.4103/0970-9290.147105

[39] Balbino, C.A., Pereira, L.M. and Curi, R. (2005) Mechanisms Involved in Wound Healing: A Revision. Revista Brasileira de Ciências Farmacêuticas, 41, 27-51. https://doi.org/10.1590/S1516-93322005000100004

[40] Liang, H., Vu, K.T., Trang, T.C., et al. (1997) Giant Cell Formation in Cells Exposed to $740 \mathrm{~nm}$ and $760 \mathrm{~nm}$ Optical Traps. Lasers in Surgery and Medicine, 21, 159-165. https://doi.org/10.1002/(SICI)1096-9101(1997)21:2<159::AID-LSM7>3.0.CO;2-P

[41] Kyriakides, T.R., Foster, M.J., Keeney, G.E., et al. (2004) The CC Chemokine Ligand, CCL2/MCP1, Participates in Macrophage Fusion and Foreign Body Giant 
Cell Formation. The American Journal of Pathology, 165, 2157-2166.

https://doi.org/10.1016/S0002-9440(10)63265-8

[42] Novoselova, E.G., Cherenkov, D.A., Glushkova, O.V., et al. (2006) Effect of Low Intensity Laser Radiation (632.8 nm) on Immune Cells Isolated from Mice. Biofizika, 51, 509-518. https://doi.org/10.1134/S0006350906030195 